\title{
Inter-professional education: Healthcare students' experiences
}

\author{
Heila van Wyk, BOccTher (UP), MOcc Ther (UP) \\ Junior Lecturer Dept. pf Occupational therapy University of Pretoria at the time the study was conducted, Occupational therapists \\ in private practice
}

Marianne de Beer, Nat Dip OT (Pret), Dip Ed Voc Ther (UP), MOccTher (UP), PhD (MEDUNSA), PhD (UP) Senior lecturer, Department of Occupational Therapy, University of Pretoria

Introduction: Inter-professional education has been identified as a strategy to overcome some challenges facing healthcare throughout the world. The aim of inter-professional programmes within institutions of higher education is to improve teamwork between healthcare professionals. Different professionals with a variety of skills are required to work effectively in a team for comprehensive and cost-effective healthcare. A number of research studies have investigated the outcomes of inter-professional education, but limited information is available to explain the mechanisms that led to these outcomes. This study could assist Inter-Professional Education (IPE) facilitators at institutions of higher education when developing and implementing IPE programmes.

Method: Qualitative data of the final-year healthcare students' experiences of an inter-professional education programme were generated by means of a reflective essay. The essays were completed after participating in an inter-professional education programme and thematically analysed.

Findings and conclusion: The findings of the study generated three main themes: the first theme was the outcomes of interprofessional education as experienced by the healthcare students, the second identified an environment in which teamwork was promoted, and the third identified certain attributes that team members needed for effective teamwork. The second and third themes were identified as mechanisms that lead to the outcomes described in theme one. It is recommended that facilitators of inter-professional education implement these mechanisms for optimal teamwork.

Key words: Inter-professional education, healthcare student, qualitative, teamwork, mechanisms, outcomes

\section{INTRODUCTION}

Effective teamwork amongst healthcare professionals is considered essential to address the complex healthcare needs currently experienced worldwide'. The World Health Organization has identified inter-professional education (IPE) as an educational strategy that could play a significant role in facilitating teamwork amongst health workers and in turn alleviate many healthcare challenges'. The World Health Organization's Framework for Action on Interprofessional Education and Collaborative Practice states that "inter-professional education occurs when two or more professions learn about, from and with each other" $1: 10$ for effective teamwork. Since teamwork is seen as a skilled action, an educational strategy identified as IPE, is therefore needed ${ }^{2}$. IPE aims to enhance the knowledge, skills and behaviour needed for improved teamwork among health professionals ${ }^{3}$.

In previous years, the tendency was for healthcare professionals to be educated in silos; consequently they had little exposure with other professionals, which made collaboration difficult ${ }^{2}$. However, the need to teach healthcare students to function optimally in a team is emphasised increasingly in institutions of higher education ${ }^{1,3,4}$. This focus on IPE in institutions of higher education has also led to an increase in research that evaluates the IPE programmes and initiatives ${ }^{5}$. A systematic literature review covering 21 articles on "the strongest evaluations of IPE", recommends that more studies be conducted to understand the mechanisms in the IPE programme which lead to positive behavioural changes and improved patient care $^{6}$. Reeves et al. ${ }^{7}$, who also conducted a systematic review, similarly recommend that studies should give insight into how IPE affected the changes and outcomes and this could be done through qualitative methods ${ }^{7}$. Research further recommends that learning can only take place once students' learning requirements are met ${ }^{8}$. IPE facilitators should therefore aim to understand the students' learning experiences or learning needs during inter-professional teamwork $^{8}$.

\section{BACKGROUND}

The need for inter-professional teamwork was identified as a required outcome for the undergraduate healthcare students' community fieldwork block at a University in South Africa. Final-year occupational therapy, physiotherapy and speech therapy students were expected to work together one morning per week at a care center for children diagnosed with cerebral palsy $(\mathrm{CP})$.

No formal attempts to facilitate inter-professional teamwork amongst the undergraduate healthcare students was previously done in this setting. The need for specific knowledge and skills to function effectively within a team was however identified'. Furthermore, an IPE programme was identified as a suitable means to facilitate teamwork among these healthcare students. This IPE programme was developed and implemented by the clinical supervisor.

The IPE programme, developed for a centre where fieldwork supervision was undertaken, consisted of several activities and participation in these activities was compulsory. Students were divided into teams of three to five members, and two to three patients were allocated per team. As far as was practically possible, the teams included students from various disciplines. Teams continued to work together for three morning sessions and treated the same patients. At the beginning of the session the teams had to participate in a team-building activity of approximately $I 0$ to $I 5$ minutes which was aimed at facilitating interaction and lessening anxiety ${ }^{10}$ The clinical supervisor informed the students what was expected 
of them, providing them with clear guidelines for the sessions. A form containing specific details of each of the patients had to be completed before and after each treatment session involving those patients. The students had to discuss the goals for treatment and plan its implementation together before conducting the treatment session. The roles of each student in the team had to be indicated on the patient form. The team was also expected to meet after each session to evaluate progress and to plan for the next session. After treating all the patients who had been allocated to the teams, the students were required to reflect on the their morning's learning experiences in the larger student group 6 .

The main aim of the study was to identify the mechanisms that led to the outcomes experienced by the students. Ultimately, the findings of the study could assist IPE facilitators during the development and implementation of IPE programmes. A qualitative study was conducted to produce a rich source of information that relates well to the complex processes of IPE 7 .

\section{METHODS}

A qualitative research design was employed to determine the experiences of the healthcare students after being exposed to an IPE programme for a period of three contact sessions, as well as what the possible reasons/mechanisms for these experiences could have been. Ethical clearance was obtained from the University's Faculty of Health Sciences Research Ethics Committee (UP Rec 369/20I4).

\section{Sampling}

A purposive sample was used and a total of 20 final-year undergraduate students were invited to participate. Voluntary consent was given by 19 students. The sample consisted of 12 occupational therapy students, five speech and language pathology students and two physiotherapy students.

\section{Data collection}

The students were then invited to complete a reflective essay that comprised three open- ended questions about the students' experiences of the IPE programme after the IPE programme had been implemented for three mornings. The three open-ended questions were the following:

I. Reflect on your experiences as a team member in this particular setting.

2. Reflect on development over the last three Wednesdays from being exposed to working mainly individually (or with your own discipline) to working in a team with other disciplines.

3. Anything else that you would like to mention.

A reflective journal of the IPE programme was kept during the researcher's facilitation and the researcher's own role in collecting and creating interpretations of data was noted in the reflective journal ${ }^{11,12}$. The reflective journal was used to enhance the transparency of the research process since bias or researcher influence continues to be a very real concern in qualitative research ${ }^{13}$. The reflective journal was therefore used for critical reflection during the research process.

\section{Data management}

Due to the involvement of the researcher in the process an independent person was asked to assist with the collection and management of the data. During data collection the researcher explained the information leaflet and procedure to the students after which he left the session. An independent occupational therapist was responsible for handing the reflective essays to the students and for collecting them after completion. The researcher was available telephonically for any questions or queries.

After voluntary consent was given the independent therapist allocated a number to each student. The list of the students' names with the different numbers that were allocated was kept with the independent therapist throughout the data collection and analysis. This procedure was also described to the students to make it clear that the researcher would not be able to identify the students in the reflective essays. The independent therapist then scanned and emailed the essays to the researcher.

\section{Data analysis}

The data generated from the reflective essays were analysed using thematic analysis ${ }^{\prime 2}$. The cut-and-sort manual processing technique was also used as this is a versatile technique to generate themes ${ }^{14}$. Two techniques were therefore used in the analysis since using only one technique could limit the richness of the themes generated or focus the themes on what is already known to the researcher ${ }^{14}$. After the themes were identified an independent reviewer was asked to review the themes to enhance credibility as the researcher was also the facilitator of the IPE programme. The independent reviewer made valuable suggestions which were incorporated into the results.

\section{FINDINGS}

The focus of the research was not only to describe the experiences of the students during inter-professional teamwork, but also to identify mechanisms that were responsible for the students' experiences during the three days of inter-professional education. Three themes were identified from the data, in which the first theme consisted of the outcomes that the students experienced, whereas the second and third themes identified the mechanisms that led to the outcomes experienced in theme one. The three themes identified were: I) the outcomes of teamwork, 2) an environment promoting inter-professional teamwork, and 3) the attributes of the team members themselves. Figure $/$ illustrates the themes and categories derived from this study.

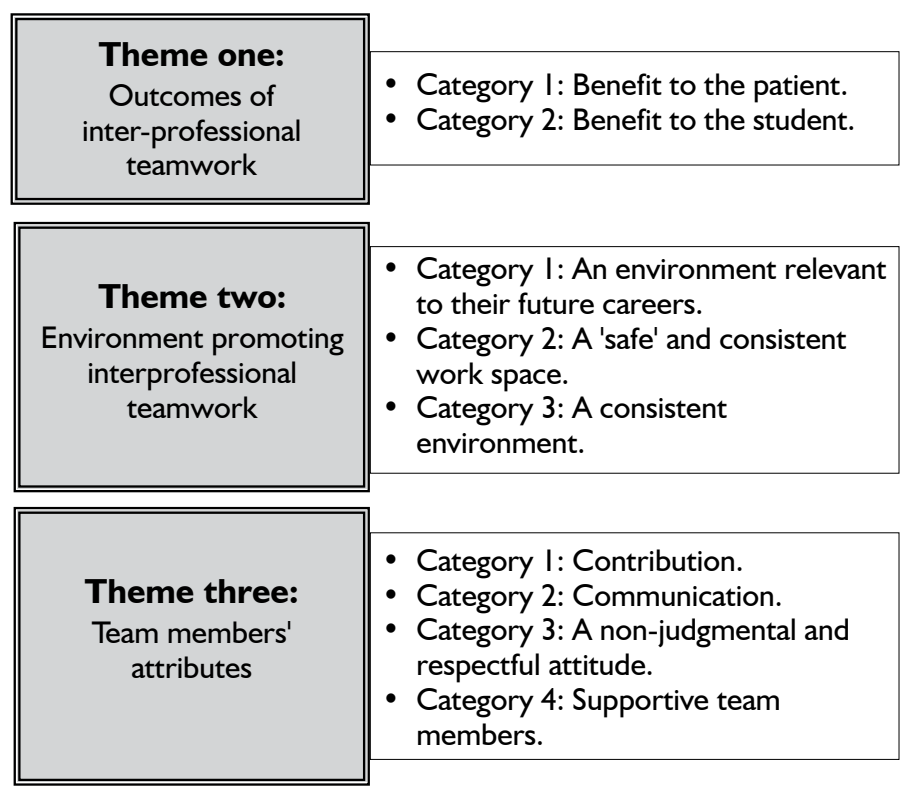

Figure I: Summary of themes and categories of the study

The themes and categories that emerged from the study are discussed below.

\section{Theme one: Outcomes of inter-professional teamwork}

The reflections of the students indicated two categories related to the outcomes they experienced ie category I - the beneficial effect of teamwork on patient care, and category 2 the beneficial effect on the students.

Category I: The benefit of teamwork to the patient was highlighted in phrases such as "each session showed progress", "see the influence of teamwork on the client" and "see the effect of a team on the treatment". These responses clearly indicated that the students had observed improvement in patient care. One of the students commented as follows: 
"I have learned how good it is to work in a team, things I observed during the week with regard to mouthing we incorporated with the feeding and it worked well as our client could feed herself, it was awesome to see it and I felt very proud about how well our teamwork influenced the outcome of our client." (Occupational therapy student (OT3))

Although improvement in patient care was observed, the real impact on the patient was not measured.

Category 2 The students experienced teamwork as beneficial not only for the patients but also for themselves as they experienced development through "learning" and "growth" during the four weeks. The learning and growth that took place was further subdivided into various subcategories which included professional, social and personal learning which are described separately below.

Sub category I: Professional learning was prominent during the four weeks as all 19 of the students (100\%) indicated some form of professional learning over this time. Students learned specific aspects about the assessment, treatment, roles and scopes of the other professions:

"I have really learnt a lot from other team members over the last 3 weeks. With speech therapists, l've learnt different feeding techniques (e.g. side feeding). From physios [physiotherapy students] l've learnt how they check for aspiration on the lungs. From fellow OT's [occupational therapy students] l've learnt different position techniques with different children." (OT9)

The students made it clear that they did not only learn about the other professions, but also about their own:

"This was an extraordinary learning experience for me personally not only did my knowledge on other disciplines increase, but also my knowledge and abilities in my own discipline." (Physiotherapy student (PTI3))

The students also found that they knew more than they thought, and this improved their confidence and also made them feel proud of their profession:

"As the weeks progressed, I experienced that the different members not only gained more confidence in their own skills but we also became more comfortable to share our knowledge with each other." (STI5)

"I personally developed by being proud of my profession and realising how much I already know." (OT5)

Sub category 2: Social learning was also experienced by the students. As the weeks progressed, they felt comfortable about interacting with others; and formed new "professional friends". The importance of building relationships was highlighted by the following comment:

"I gained more professional friends and colleagues that I can consult, when needed, in the future." (Speech therapy student (STI7))

Sub category 3: When personal learning was experienced the students' previous perspectives on teamwork was also changed:

"I have transformed my way of thinking about teamwork and in how we as professionals should know each other's roles and be able to refer appropriately in the future." (STI6)

The students realised the importance of working within a team as opposed to working alone:

"Initially I preferred working alone but in this setting I would not have it any other way [...] I also got to answer their questions which in turn also taught me a lot as I realised I know more than I think I do." (PTI4)

The benefit to the student as identified in these three sub-categories of professional, social and personal learning, could also further guide the IPE facilitator about the learning needs of the students.

The next two themes of this study indicated which mechanisms, according to the students, led to the outcomes mentioned in theme one. These themes are in line with Hammick et al.' $\mathrm{s}^{6}$ recommendation that it is essential to know what mechanisms lead to these outcomes. An environment promoting inter-professional teamwork was identified as theme two, and team members' attributes were identified as theme three. Both themes are interlinked and were described as important mechanisms that led to the outcomes experienced, and as described in theme one. The interlinked mechanisms were however divided into two themes to assist the facilitator in facilitating IPE in the future. Theme two focused on the environment that is needed to promote inter-professional teamwork and theme three focused on what the team members should add to the team in order for teamwork to be effective.

\section{Theme two: An environment promoting inter- professional teamwork}

Where student preferred the environment to be relevant to their future careers (category I), to be a so-called safe or stress-free workspace (category 2) and a consistent one (category 3 ).

Category I: An environment relevant to the students' future careers is identified as one that is essential for promoting inter-professional teamwork:

"I realised that in the case of CP children, theory differs extremely from practice; therefore it is of utmost importance to incorporate teamwork to get as much input as possible for effective patient treatment." (PTI3)

“... it's really going to help me in the future as well. I would like to work one day in [a] team and this has shown me how to start doing this." (OT9)

Category 2: A safe or stress-free work space was also identified as an environment promoting inter-professional teamwork in which the students could share and practice without fear of making mistakes or receiving bad marks:

"It was also a safe zone as we as students had the opportunity [to work as a team] without having marks given against us." (OT3)

Students also experienced the inter-professional teamwork sessions as a safe work space because they were not being assessed.

Category 3: The students also suggested that a consistent environment could promote inter-professional teamwork, and as one student mentioned:

"It was especially good to be in the same team for this whole time." (OTI2)

The importance of keeping the team consistent was confirmed by another comment of a student: "it [teamwork] also got easier as time went on".

\section{Theme three: Team members' attributes}

The students indicated essential qualities for effective teamwork ie: category I - contribution; category 2 - communication; category 3 - a non-judgmental and respectful attitude, and category 4 - supportive team members.

Category I: Contribution was indicated by phrases such as "assist with", "contribute equally", "show the others", "participate equally" and "learn how to allow each other to do". The following excerpt highlights this view:

"Not only did I feel like a valuable member of the team each week but once I knew enough about the child we worked on [...]. Finally I have learnt that teamwork can work if every member of the team contributes equally." (PTI4)

Students' contributions improved when they felt valued in the team and when all the team members contributed equally.

Category 2: Communication was described as "transfer own knowledge to others", "sharing information and ideas", "interact", "ask questions", "say your say", "share our knowledge", "effective communication" and "put my points of view forward".

Category 3: A non-judgmental and respectful attitude was also identified as essential team attributes. Students should be accepting, open and respectful towards other students:

"It is important to have respect for each other and their roles so that 
in therapy they can support one another and make therapy most effective [...] I also expect no judgement from the others but support from everyone." (STI9)

According to the students this attitude led to an increase in interaction and sharing and ultimately an improvement in teamwork:

"It was easier to interact and ask questions to the students from the other disciplines especially because it felt that we respected each other." (OT6)

A non-judgmental environment where students felt respected increased interaction in the teams.

Category 4: Supportive team members are also essential to enhance teamwork. Phrases and words such as to "support each other", "encourage", "guidance", "helpful" and "working together" described the need for a supportive team. The students noticed that they were less shy and more competent and confident to try new things when they were able to work as a team and when they felt they were supported by their peers:

"I feel less shy and more competent as we supported each other and encouraged each other and success was seen." (STI9)

Contributing in the team, communicating to team members, having a non-judgemental and respectful attitude as well as being a supportive team member are all essential attributes for optimal teamwork.

\section{DISCUSSION}

The first theme was identified by the students as the outcome of inter-professional education. The categories of the first theme were described as its benefit to the patient and benefit to the students. The students mentioned that the patients should be the focus point of teamwork and should therefore benefit from inter-professional teamwork (category I). Similarly, in another study an overwhelming number of participants identified the patient as the main focus of teamwork ${ }^{15}$. Furthermore, the students noted the importance of participating in more IPE activities as this could result in improved patient care ${ }^{16}$. Even though the effect of IPE on patient care was not directly measured in this study, patient care was still identified as an important focus in teamwork.

The students experienced teamwork as beneficial not only for the patient but also for themselves. The benefit to the student was identified as the first category of the outcome of inter-professional teamwork. Reeves and Freeth ${ }^{8}$ recommended that learning can only take place once students' learning requirements are met. IPE facilitators should therefore understand the students' experiences as learning takes place once students' learning needs are met $^{8}$. Learning and growth was reported on a professional, social and personal level, which was identified as subcategories of the second category, the benefit to the student.

On a professional level, improved confidence, knowledge and skill was also reported after participation in IPE ${ }^{17}$. Gaining knowledge about team members' roles is seen as an essential outcome of IPE ${ }^{15,18}$ as improved knowledge about members' roles could lead to improved teamwork and communication ${ }^{17}$. Since students also realised that they knew more than they had thought, they gained greater confidence and it engendered pride in their profession. Pride in their profession came with the realisation of the importance of their own role ${ }^{16}$. Students valued gaining knowledge about the roles of the different professions as these roles were often unclear in the team ${ }^{19}$. Improved knowledge of team members' roles and responsibilities also tend to have positive effects on the patient's treatment ${ }^{16}$ and the student's clinical experience ${ }^{20}$. IPE programmes should therefore include activities where team members can gain knowledge about one another's roles as such an approach does not only lead to professional learning for the student but could also improve patient care.

Social learning and growth such as enhanced communication skills were reported ${ }^{17}$. Evidence of health professionals' communication improving even after one short half-day IPE session was reported in a study ${ }^{17}$. The students also highlighted the importance of meeting new possible future colleagues. The students in our study experienced improved communication and gaining new professional friends as being important for social learning.

The students reported a transformed way of thinking about teamwork, which resulted in personal growth. Confidence was identified as being essential for personal growth and also vital for collaboration ${ }^{6}$.

As mentioned, the aim of this study was not only to report on the outcomes of IPE but also on the mechanisms that led to these outcomes according to the students' experience. In this research process, an environment promoting inter-professional teamwork (theme two) and team members' attributes (theme three) were the mechanisms that resulted in these outcomes.

Students described the categories of the second theme, an environment promoting inter-professional teamwork, as being I) relevant for future careers 2) a safe workspace and a 3) consistent environment.

When IPE is conducted in a clinical placement or has benefits for the students' future careers, they are also more likely to experience IPE as positive ${ }^{16,21}$. The first category of an environment promoting inter-professional teamwork (theme two) was found to be beneficial to the students' future careers. The importance of students identifying the IPE activities as relevant for their future careers should not be underestimated ${ }^{16,22}$. On the other hand, Buckley et al. ${ }^{23}$ found that different student groups identified different benefits from IPE. One example was that medical students did not mention improved confidence to communicate in a team after an IPE stimulation activity, whereas all the other professions did. There could have been several reasons for this variation in the results, one being that different professionals have different learning requirements for IPE ${ }^{17}$. It is therefore essential for IPE facilitators to address the learning needs and expected learning outcomes of the healthcare students in a relevant context ${ }^{24}$.

The students identified the inter-professional teamwork as a safe workspace. A safe workspace was seen as the second category of an environment promoting inter-professional teamwork. Since no assessment took place during the IPE the students felt comfortable when asking questions within the team without fear of failure ${ }^{16}$. When students experience anxiety when they are assessed, such a situation could result in diminished participation and interaction and ultimately cause less collaboration in the team ${ }^{16}$.

Students also preferred a consistent work environment (category three of the second theme). Interaction was enhanced when teams were consistent during IPE. Facilitators should therefore safeguard stability in a group by ensuring the team members remain unchanged during IPE ${ }^{25}$ as a consistent environment could lead to improved communication.

The second mechanism that resulted in the positive outcomes discussed in theme one was that team members should have specific attributes for optimal teamwork. The team members' attributes were identified as the third theme. Students listed I) contribution, 2) communication, 3) a non-judgemental and respectful attitude and 4) supportive team members as the four categories of essential team member attributes for effective teamwork.

Contribution (category one) tends to motivate team members to participate even more meaningfully in the team as it enhances team members' confidence and improves teamwork. The students also identified the importance of equal contributions among team members in order to promote collaboration ${ }^{16}$. Contribution facilitated trust in the team ${ }^{26}$ as members felt their contributions were respected and they felt valued ${ }^{16}$. The observation that team members could be valuable and resourceful to a team is essential for collaboration ${ }^{5,27}$.

After participating in IPE, the students also expressed the importance of communication (category two) for effective teamwork $^{16,28,29}$. Patients are more likely to receive quality care when team members are able to communicate effectively ${ }^{30}$. McPherson et al. ${ }^{31}$ state that for teamwork to be effective, team members 
needed good interpersonal skills such as communication, sharing and listening. Poor communication skills have been identified as a major factor hindering teamwork ${ }^{31}$. Although communication skills are vital for effective teamwork, according to the available literature, little time is currently spent in most tertiary institutions on training students to improve their communication skills ${ }^{9,32}$. Students highlighted that confidence and communication are closely related. Communication, together with contribution in a team, was identified as an important aspect of successful teamwork and for ultimately attaining positive outcomes.

Students preferred an attitude of openness, respect and support as this led to improved confidence, interaction and sharing in the team. A non-judgmental and respectful attitude was identified as the third category of essential attributes of team members (theme three). A team can only function effectively when team members trust, appreciate and respect one another ${ }^{20}$. Mutual respect among the team members is essential for effective collaboration ${ }^{33,34}$ and important that for effective teamwork, a co-operative, non-judgmental environment should be created. According to the students, a nonjudgmental and respectful attitude encourages students to interact more within the team, thereby improving teamwork.

Students mentioned supportive team members as the fourth category of essential attributes of team members (theme three). A safe environment encourages students to share more freely as they tend to trust their own abilities without feeling exposed to judgment. Hammick et al. ${ }^{6}$ similarly suggest that IPE activities be conducted in a safe, organised and supportive environment. Students tend to be anxious when they feel exposed to possible judgment by their peers $\mathrm{s}^{6,17,35}$.

It is recommended that facilitators of IPE should take note of the outcomes of inter-professional teamwork including the learning experiences as highlighted in theme one. Findings as identified in theme two could be incorporated when the facilitators plan an IPE programme as these components could be facilitated during IPE through structure and planning, The IPE facilitator should also give attention to the third theme as these are skills identified to work within a team.

\section{Limitations}

As the sample size was relatively small and all the professions were not equally represented, the data of students from different professions could not be analysed individually ${ }^{17}$. The study did not focus on whether the IPE programme could be linked directly to the outcomes experienced as other aspects may have had an impact on the students' learning and growth. If the IPE programme did in fact facilitate improved teamwork, the question is still: which components of the programme resulted in which experienced outcomes? Another possible limitation was that the researcher was also the facilitator of the IPE and known to one of the healthcare student groups. A reflective journal was kept by the researcher to prevent bias as far as possible.

\section{CONCLUSION}

Much has been reported in the literature on the possible outcomes of IPE but little has been said about the mechanisms that brought about these outcomes. This study reports on the outcomes and the mechanisms after final-year healthcare students participated in three IPE contact sessions.

The findings may be used to guide facilitators of IPE to facilitate teamwork among healthcare students by applying the mechanisms identified. IPE facilitators will, however, still need to use their own discretion, knowledge and experience to apply these mechanisms in their particular contexts. Further research is needed to build on the findings of this study. Measuring the effect of the identified mechanisms against the outcomes of patient care should also be investigated as what this research article revealed is only the tip of the iceberg.

\section{Declaration of interest}

The authors reported no declaration of interest.

\section{ACKNOWLEDGEMENT}

We would like to thank $\operatorname{Dr} C$ Maree and Prof. C Kapp for their guidance during the study. We are grateful to the independent coder, Mrs L Grobler, the critical reader Ms C Marshall Cloete and the editor Ms E Belcher for their assistance. The participation of the healthcare students is also appreciated.

\section{REFERENCES}

I. The World Health Organisation . Framework for action on Interprofessional Education and Collaborative Practice. Geneva: WHO Press; 2010.

2. Carlisle C, Cooper H, Watkins C. "Do none of you talk to each other?": the challenges facing the implementation of inter-professional education. Med Teach. 2004; 26(6): 545-52.

3. Gilbert JH, Yan J, Hoffman SJ. A WHO report: Framework for action on inter-professional education and collaborative practice. J Allied Health. 2010; 39(Supplement I): 196-7.

4. Wilhelmsson M, Pelling S, Ludvigsson J, Hammar M, Dahlgren L-O, Faresjö T. Twenty years experiences of inter-professional education in Linköping-ground-breaking and sustainable. J Interprof Care. 2009; 23(2): I2I-33.

5. Mellor R, Cottrell N, Moran M. "Just working in a team was a great experience..." - Student perspectives on learning experiences of an inter-professional education program. J Interprof Care. 2013 ;27: 292-7.

6. Hammick M, Freeth D, Koppel I, Reeves S, Barr H. A best evidence systematic review of inter-professional education: BEME Guide no. 9. Med Teach. 2007; 29(8): 735-5I.

7. Reeves S, Zwarenstein M, Goldman J, Barr H, Freeth D, Koppel I, et al. The effectiveness of inter-professional education: Key findings from a new systematic review. J Interprof Care. 20 I0; 24(3): 230-4I.

8. Reeves $\mathrm{S}$, Freeth $\mathrm{D}$. The London training ward: an innovative interprofessional learning initiative. J Interprof Care. 2002; I6(I): 4I-52.

9. Hall P, Weaver L. Interdisciplinary education and teamwork: a long and winding road. Med Educ. 200I; 35(9): 867-75.

10. Bridges DR, Davidson RA, Odegard PS, Maki IV, Tomkowiak J. Inter-professional collaboration: three best practice models of inter-professional education. Med Educ Online. 20II; 16.

II. Blanche MJT, Blanche MT, Durrheim K, Painter D. Research in practice: Applied methods for the social sciences. Juta and Company Ltd; 2006.

12. Bryman A. Social research methods. Oxford University Press; 2012.

13. Ortlipp M. Keeping and using reflective journals in the qualitative research process. Qual Rep. 2008;13(4):695-705.

14. Ryan G, Weisner T. Analyzing words in brief descriptions: Fathers and mothers describe their children. Cul Anthr Meth J. 1996; 8(3): 13-6.

15. Doll J, Packard K, Furze J, Huggett K, Jensen G, Jorgensen D, et al. Reflections from an inter-professional education experience: Evidence for the core competencies for inter-professional collaborative practice. J Interprof Care. 2013; 27(2): I 94-6.

16. Mellor R, Cottrell N, Moran M. "Just working in a team was a great experience..."-Student perspectives on the learning experiences of an inter-professional education program. J Interprof Care. 2013; 27(4): 292-7.

17. Buckley S, Hensman M, Thomas S, Dudley R, Nevin G, Coleman J. Developing inter-professional simulation in the undergraduate setting: experience with five different professional groups. J Interprof Care. 20I2; 26(5): 362-9.

18. Pirrie A, Wilson V, Elsegood J, Hall J, Hamilton S, Harden R, et al. Evaluating multidisciplinary education in health care. Edinburgh: Scottish Council for Research in Education; 1998.

19. Parsell G, Bligh J. Inter-professional learning. Postg Med J. 1998; 74(868): 89-95.

20. Treadwell I, Van Rooyen $M$, Havenga $H$, Theron $M$. The effect of an inter-professional clinical simulation on medical students. Afr J Health Prof Educ. 2014; 6(I): 3-5.

21. Parsell G. Educational principles underpinning successful shared learning. Med Teac. 1998; 20(6): 522-9.

22. Reeves S, Goldman J, Oandasan I. Key factors in planning and implementing inter-professional education in health care settings. J Allied Health. 2007; 36(4): 23I-5. 
23. Buckley S, Hensman M, Thomas S, Dudley R, Nevin G, Coleman J. Developing inter-professional simulation in the undergraduate setting: experience with five different professional groups. J Interprof Care. 2012; 26(5): 362-9.

24. Harden R. AMEE guide No. I2: Multiprofessional education: Part I-effective multiprofessional education: a three-dimensional perspective. Med Teach. 1998; 20(5): 402-8.

25. Freeth D, Nicol M, Reeves S, Wood D. Education for clinical governance: an inter-professional approach. J Interprof Care. 2000; 14(3): 292.

26. Jones GR, George JM. The experience and evolution of trust: Implications for cooperation and teamwork. Academy of management review. 1998; 23(3) :531-46.

27. McPherson K, Headrick L, Moss F. Working and learning together: good quality care depends on it, but how can we achieve it? Qual Health Care. 200 I; 10(suppl 2): ii46-ii53.

28. Forte A, Fowler P. Participation in inter-professional education: An evaluation of student and staff experiences. J Interprof Care. 2009; 23(I): 58-66.

29. O'Carroll V, Braid M, Ker J, Jackson C. How can student experience enhance the development of a model of inter-professional clinical skills education in the practice placement setting? J Interprof Care. 20I2; 26(6): 508-10.

30. Knebel E, Greiner AC. Health Professions Education: A Bridge to Quality. National Academies Press; 2003.

31. McPherson K, Headrick L, Moss F. Working and learning together: good quality care depends on it, but how can we achieve it? Qual Health Care. 2001; I0(suppl 2): ii46-ii53.

32. Pfrimmer D. Teamwork and communication. J Contin Educ Nurs. 2009; 40(7): 294.

33. Ateah CA, Snow W, Wener P, MacDonald L, Metge C, Davis P, et al. Stereotyping as a barrier to collaboration: Does inter-professional education make a difference? Nurse Educ Today. 20 I I; 3 I (2): 20813.

34. Papinczak T, Young L, Groves M. Peer assessment in problem-based learning: A qualitative study. Adv Health Sci Educ. 2007; I2(2): 169 86.

35. Morison S, Jenkins J. Sustained effects of inter-professional shared learning on student attitudes to communication and team working depend on shared learning opportunities on clinical placement as well as in the classroom. Medl Teac. 2007; 29(5): 450-6.

\section{Corresponding author}

\section{Heila van Wyk}

heilavw@gmail.com 